\title{
Erratum to: Active and Programmable Networks
}

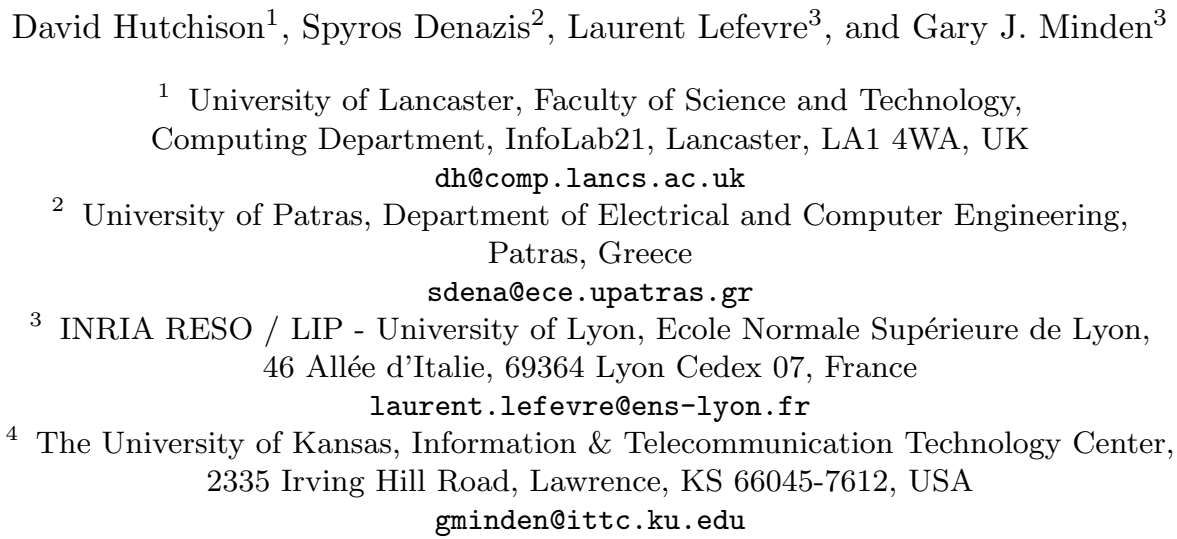

\section{Erratum to:}

D. Hutchison et al. (Eds.) Active and Programmable Networks DOI: $10.1007 / 978-3-642-00972-3$

The book was inadvertently published with an incorrect name of the copyright holder. The name of the copyright holder for this book is: (c) IFIP International Federation for Information Processing. The book has been updated with the changes.

The updated original online version for this book can be found at DOI: $10.1007 / 978-3-642-00972-3$

D. Hutchison et al. (Eds.): IWAN 2005, LNCS 4388, p. E1, 2009.

(C) IFIP International Federation for Information Processing 2017 